\title{
Correction to: Impacts of the hygro-thermo conditions on the vibration analysis of 2D-FG nanoplates based on a novel HSDT
}

\author{
Zhenya Zhang $^{1,2} \cdot$ Xiaoli Liu $^{2} \cdot$ Reza Mohammadi ${ }^{3}$
}

Published online: 14 September 2021

๑) Springer-Verlag London Ltd., part of Springer Nature 2021

\section{Correction to: Engineering with Computers https://doi.org/10.1007/s00366-021-01443-2}

In the original publication of the article, corresponding author forgot the acknowledgment part of the paper. I sincerely ask you to add this section as below:

This research is financially supported by the Natural Science Foundation of Zhejiang province, China (No. LY20A020005), preparatory funds of School of Architecture and Transportation, Ningbo university of technology, Open Research Fund Program of State key Laboratory of Hydroscience and Engineering.
The original article can be found online at https://doi.org/10.1007/ s00366-021-01443-2.

\section{Xiaoli Liu}

L13600620263@sina.com

1 School of Architecture and Transportation Engineering, Ningbo University of Technology, Ningbo 315211, China

2 State Key Laboratory of Hydroscience and Engineering, Tsinghua University, Beijing 100084, China

3 Department of Mechanical Engineering, Tarbiat Modares University, Tehran, Iran
Publisher's Note Springer Nature remains neutral with regard to jurisdictional claims in published maps and institutional affiliations. 